\title{
Borewell Rescue Robot
}

\author{
V. Venmathi \\ Assistant Professor \\ ECE \\ SNS College of Engineering \\ Coimbatore, Tamil Nadu.
}

\author{
E. Poorniya \\ Student of Final year \\ ECE \\ SNS College of Engineering \\ Coimbatore, Tamil Nadu.
}

\author{
S. Sumathi \\ Student of Final year \\ ECE \\ SNS College of Engineering \\ Coimbatore, Tamil Nadu.
}

\begin{abstract}
The aim of this project is to give an innovative concept to handle the bore well rescue operations. Nowadays child often falls down in the borehole which is left uncovered and get trapped. It is difficult and also risky to rescue the trapped children to aid in such rescue we proposed a system of designing robots to the rescue of a child in a borehole. The robot structure consists of power supply, switch pad, gear motors, Oxygen concentrator, camera and Microcontroller. The condition of trapped child is captured with CCTV camera and monitored on a TV. A safety balloon is introduced in order to provide extra safety. Once the lifting rod reaches a safe position under the child, an air compressor is operated to pump air to the bladder attached to the end of the lifting rod through an air tube that runs downwards inside the lifting rod. The bladder provides a safe seating to the child. When the child is secure, the lifting rod is contracted to its maximum position. The motor is then reversely operated so as to unclamp the system. Simultaneously, it is lifted out of the well using a chain or rope. The programming language is Embedded $\mathrm{C}$ which is executed by MP lab Integrated Development Environment. This robot type machine can rescue trapped body from the bore well in a minimum amount of time and safety.
\end{abstract}

\section{Keywords}

Digital camera, Oxygen Concentrator, PIC Microcontroller, Robot design, Safety balloon

\section{INTRODUCTION}

Today's major problem faced by human society is water scarcity, which leads to a large number of bore wells being sunk. These bore wells in turn have started to take many innocent lives. Bores which yielded water and subsequently got depleted are left uncovered. Small children without noticing the hole dug for the bore will slip in and get trapped. There is no proper technique to rescue victims of such accidents. When the make shift local arrangements do not work. In most cases reported so far, a parallel hole is dug and then horizontal path is made to reach to the subject's body. It is not only a time taking process, but also risky in various ways.

Moreover, it involves a lot of energy and expensive resources which are not easily available everywhere and in this process, we always need big space around the trapped bore that we can dig a parallel bore. These ad-hoc approaches involve heavy risks, including the possibility of injuries to the body of the subject during the rescue operation. Also, the body may trap further in the debris and the crisis deepens even more means death. In most cases, we rely on some make shift arrangements. This does not assure us of any long term solution. In such methods some kind of hooks are employed to hold the sufferers clothes and body. This may cause wounds on the body of the subject. After studying all the cases we found a serious issue to do, to make a such robotic machine which can go through the trapped bore well without any support and grasp the trapped body at least minimum time with providing facilities of oxygen cylinder, safety balloon. With this machine, there is no chance of damaging human body and other minor damages, and we called that machine as "Bore Well Child Saver Machine".

\section{LITERATURE SURVEY}

The primary use of robots includes searching for survivors, where unusual viewpoints can be perceived with better human-robot interaction. Usual method followed by the rescue team is first to find the depth of the child in the bore well by using rope. After finding the depth, a parallel pit is dug using Earthmoving vehicles. This method of rescuing has following difficulties, It takes up to 30 hours to dig the parallel pit, by that time the child would have died. Lack of oxygen inside the bore well. Lack of visualization causes the major difficulty during the rescue operation There is no such special equipment for rescuing the child trapped inside the bore well.

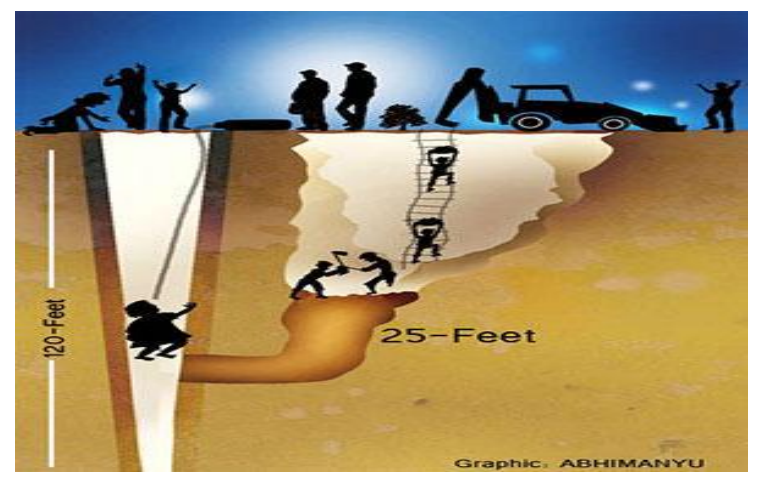

Figure 1: Army members working for the borehole rescue

Forty five deaths of children have been reported in the country since September 2009, from that we have only nineteen with the proof of a newspaper. In the year of $2012 \mathrm{Six}$ year old boy was rescued from the bore well, but later died in the hospital due to injuries during the rescue operation and lack of medical aid. Their deaths are caused due to uncovered dry bore wells.

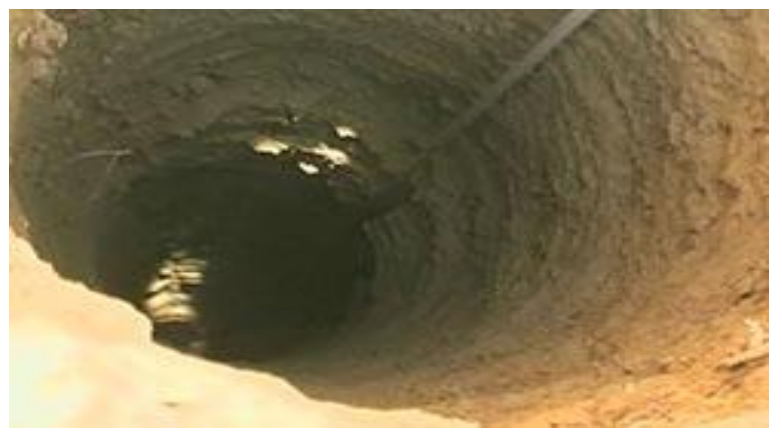

Figure 2: Depth of a Borehole 


\section{BLOCK DIAGRAM}

\subsection{Robot Module}

This unit comprises of $12 \mathrm{~V}$ power supply, switch pad and gear motors, safety balloon, solenoid valve. The switch pad has four micro switches connected to the microcontroller $\mathrm{I} / \mathrm{O}$ pins. One end of the switch is grounded and the other is connected to the microcontroller port. When any switch is pressed that particular port is grounded. The microcontroller is always monitored these switches, in real time.

\subsubsection{Motor}

A DC motor is used to convert electrical energy to mechanical energy, very typically through the interaction of magnetic field and current carrying conductors. The reverse process producing electrical energy from mechanical energy, is accomplished by an alternator, generator or dynamo. Many types of electric motors can be run as generators, and vice versa. The input of DC motor is current/voltage and its output is torque (speed). The DC motor has two basic parts the rotating part that is called the armature and the stationary part that includes coils of wire called the field coils. The stationary part is called the stator.

\subsubsection{Solenoid Valve}

A solenoid valve is an electromechanical operated valve. The valve is controlled by an electric current through a solenoid: in the case of a two-port valve the flow is switched on or off; in the case of a three-port valve, the outflow is switched between the two outlet ports. In this project solenoid valve is used to send an oxygen to the rescue child

Solenoid valves are the most frequently used control elements in fluidics. Their tasks are to shut off, release, dose, distribute or mix fluids. They are found in many application areas. Solenoids offer fast and safe switching, high reliability, long service life, good medium compatibility of the materials used, low control power and compact design.

\subsubsection{Safety Balloon}

The safety disc is an air-filled disc that has a unique dome shaped top. The safety balloon disc is 12 " in maximum diameter. It is initially in the deflated condition, fitted with the nozzle. It is inflated, when this safety balloon is in the right position under the baby. It is used to provide support for the baby.

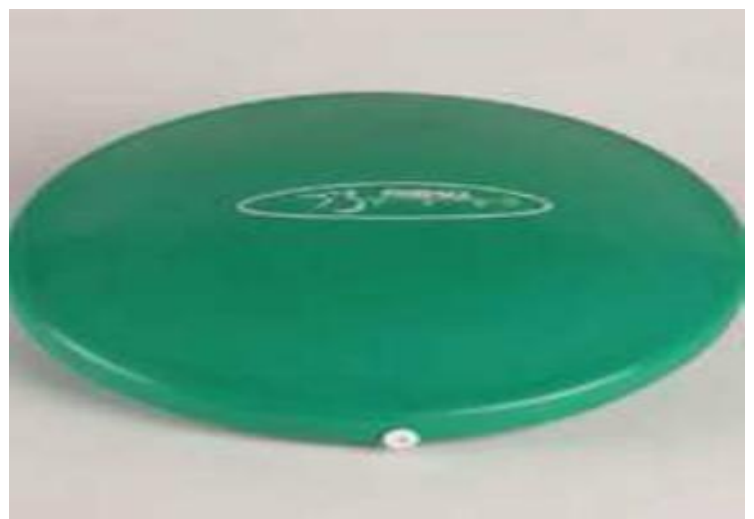

Figure 3: Safety balloon

\subsection{CCTV Camera}

Closed-circuit television (CCTV), also known as video surveillance, is the use of video cameras to transmit a signal to a specific place, on a limited set of monitors. It differs from broadcast television in that the signal is not openly transmitted, though it may employ point to point (P2P), point to multipoint, or mesh wireless links. In industrial plants, CCTV equipment may be used to observe parts of a process from a central control room, for example when the environment is not suitable for humans. CCTV systems may operate continuously or only as required to monitor a particular event. CCTV camera connected to the TV tuner. It shows the baby position inside the barrel and display on the TV.

\subsection{Advanced Digital Oxygen Supply System}

The respiration of human beings will difficult, if the percentage of oxygen in the air becomes less than $18 \%$. So, we need a device to supply proper oxygen to the baby in the rescue process. An oxygen concentrator is placed on the surface of the bore well. It will automatically sense the defect of oxygen at the rescue region and it supplies the required oxygen. For this purpose oxygen concentrator, an oxygen tube of 200meters is placed on the surface. The tube is sent along with the robot to supply emergency oxygen to baby.

\subsection{Relay}

A relay is an electrically operated switch. Many relays use an electromagnet to mechanically operate a switch, but other operating principles are also used, such as solid-state relays. Relays are used where it is necessary to control a circuit by a low-power signal (with complete electrical isolation between control and controlled circuits), or where several circuits must be controlled by one signal. The first relays were used in long distance telegraph circuits as amplifier. Relays were used extensively in telephone exchanges and early computers to perform logical operations. In this project relay is used for controlling the motor, safety balloon, oxygen supply. Based on ON/OFF state it will work.

\subsection{Controller Unit}

The unit comprises of PIC 16F877A Microcontroller. This is a RISC (Reduced Instruction Set Computing) based Microcontroller having analog input channels, analog comparators and additional timer circuits. The Microcontroller stores the information captured by the robot and display it. The temperature sensed by the robot is firstly stored in Microcontroller and then get displayed on the LCD. The video captured by the CCTV camera is displayed on a PC using Embedded $\mathrm{C}$. The serial communication between microcontroller and $\mathrm{PC}$ is done through a MAX-232 interface.

\subsection{Display Unit}

For displaying the information like temperature and smoke values, LCD (16x2) is used on each line this dot matrix LCD display module holds 32 characters-16 on each line and has a green backlight with black text.

\section{SOFTWARE REQUIREMENTS}

The Programming language is EMBEDDED $\mathrm{C}$ which is executed by MP lab IDE 


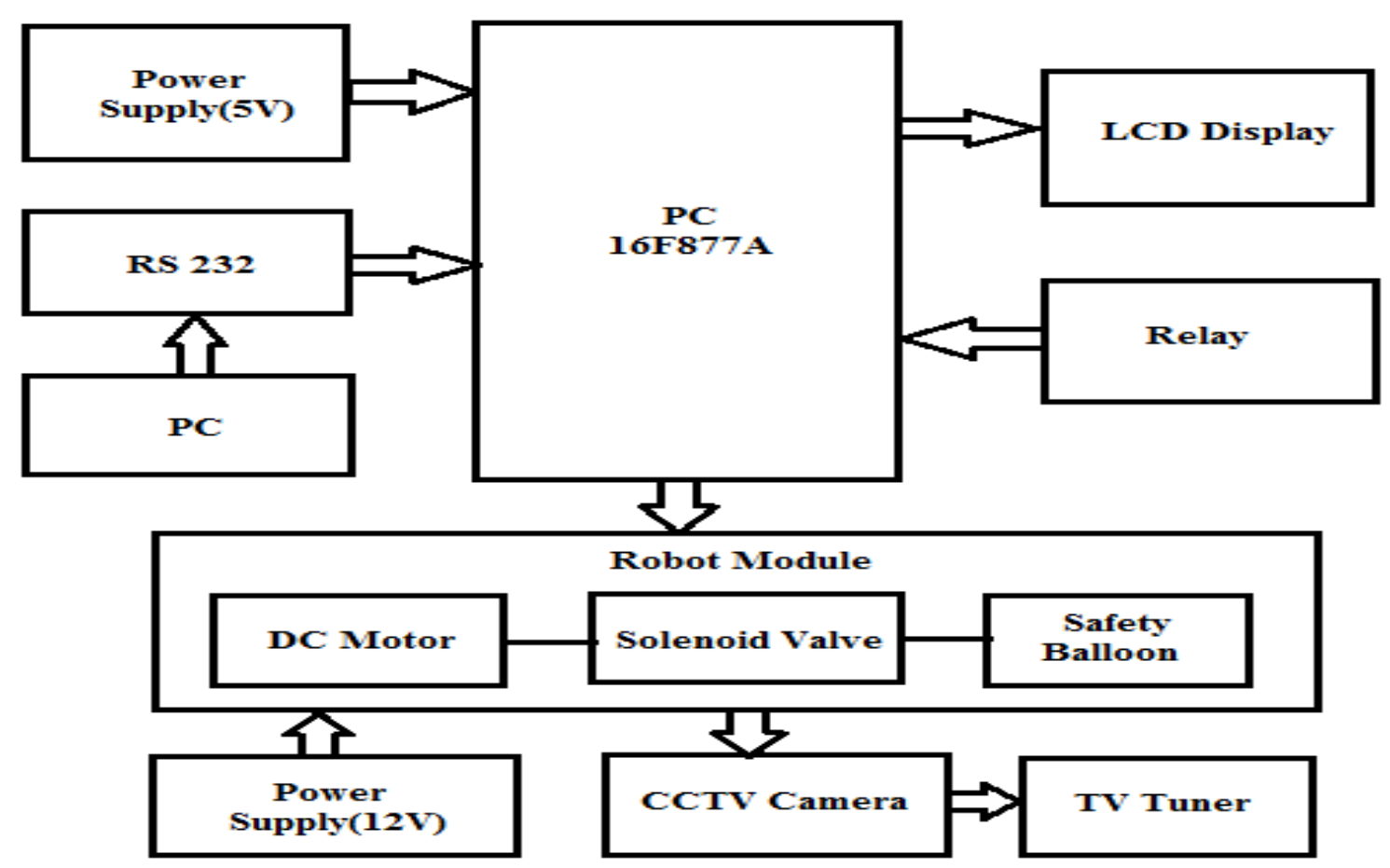

Figure 4: Block Diagram

\section{METHOD OF RESCUING}

The rope is connected to the top of the robot. As the robot is sent into the bore-well hole, electric wires for the motor from the control unit chip is attached along the rope. The oxygen hose is fixed to the upper plate of the robot. Depending on the robot movement, the hose length is adjusted from outside the bore-well. The gas hose from the compressor is connected to the gas box located on the lower plate through the hole in the upper plate. The gas box act as an intermediate gas transmitter. Using the motion detector and other special features of the camera, the baby position is seen through a computer. At the appropriate position, the fork will punch into the bore-well wall using the motor connected to the bevel gear setup on the upper plate. If the baby is trapped in the middle of bore-well, using the motor connected at the lower end of the hollow tube, the lower plate is rotated in such a way the safety balloon gas tube is in the gap between bore-well and the baby. Initially the gas tube is above the end of robot hands. It will avoid stabbing of gas tube on the baby. Using the motor connected to the pinion, the rack is moved lower than the robot hands. Then the robot is moved down in such a way that the robot hands free to hold the baby head or middle of the body. Then the safety balloon is inflated by using the air compressor through gas box. The air pressure is measured in analog pressure gauge connected to the compressor. The Digital display is placed below the upper camera. After the safety balloon reached the exact pressure, the compressor is cut off. Then the safety balloon is moved upward using motor connected to the rack and pinion setup till the safety balloon completely supports the baby. Now the baby is completely in robot control. The baby movements see through the lower camera and other data readings see through upper camera. The two way audio communication will help us to know the stipulations of the baby. Then slowly, the baby is moved upward. by pulling the rope using the pulley control system. The medical team will be able to prepare for the treatment depending on the already seen temperature of the baby. When the robot is pulled out, the rope is cut off. The robot is taken outside carefully from the stand. The hands are loosened by the motor control and the baby is taken for treatment.

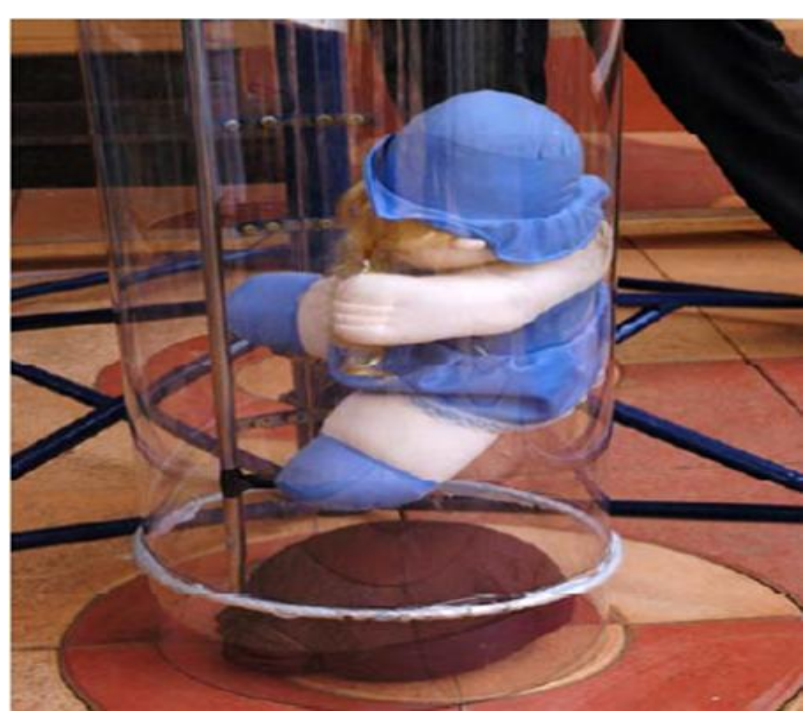

Figure 5: Balloon type Rescue System

\section{CONCLUSION}

Human life is precious. Bore well child server is a significant attempt to save the life of the victim of bore well accidents. Besides this the unique capability of climbing through vertical and inclined pipes makes wide scope of application for this machine in manufacturing industries and other relevant fields. In the current design of bore well child saver machine is has been made to suit every possible situation may occur in rescuing operation. The structure is made strong enough to sustain all possible loads, though it is made flexible at the same time to adjust wider range of bore diameter and any change in the diameter of bore. In the rescuing operation time is a vital factor which alone can determine the success or failure of the whole operation. Thus, it has been designed 
keeping the entire obstacle in mind that may arise during the operation. We like to conclude with the help of my research project I am able to rescue without any damage.

\section{FUTURE SCOPE}

In future we can use this project in several applications by adding additional components to this project. By connecting temperature sensor to the robot we can get the temperature of dangerous zones in personal computer itself instead of sending human to there and facing problems at the field, we can send robots to there and sensor will detect the temperature and it gives information to the Microcontroller and microcontroller gives the information to the transceiver from that we can get the data on the PC side.

By connecting smoke sensor to the robot we can get the information related concentration of smoke or gases in respective field's i.e (coal mines, dangerous zones, etc.) Sensor sense the information and it gives to the microcontroller and its gives to the transceiver and from that we get the information on personal computer.

\section{REFERENCES}

[1] B. Bharathi, B. Suchitha Samuel "Design and Construction of Rescue Robot and Pipeline Inspection Using Zigbee" International Journal Of Scientific, Engineering and Research (IJSER) Volume 1 Issue 1, September 2013.
[2] Sridhar Palaniswamy " Life Saving Machine" the first International Conference on Interdisciplinary Research and Development, 31 May-1 June 2011, Thailand.

[3] O. Tatar, D. Mandru, "Design of in-pipe modular robotic systems", Vol.147-149, pp. 49-54, 2009.

[4] Alan Mutka and Zdenko Kovacic "A Leg-wheel robot based approach to the solution of flipper-track robot kinematics", IEEE International Conference on Control Applications, 28-30 September, 2011, USA.

[5] Oxygen concentrator -Direct web search on google.com

[6] Safety balloon-Direct web search on google.com

[7] Camera - Direct web search on google.com

[8] J. Burke and R.R.Murphy, "Human-robot interaction in USAR technical search: Two heads are better than one,"in Proc.IEEE Int. Workshop ROMAN, Kurashiki, Japan, 2004, pp. 307-312.

[9] J. Casper and R. R. Murphy, "Human-robot interactions during the robot assisted urban search and rescue response at the world trade center," IEEE Trans. Syst., Man, Cybern. B, Cybern., Vol. 33, no. 3, pp. 367-385, Jun. 2003.

[10] R. R. Murphy, "Activities of the rescue robots at the World Trade Center from 11-21 September 2001," in Proc. IEEE Robot. Autom. Mag., 2004, pp. 50-61. 